\title{
Adrenal insufficiency presenting as hypercalcemia and acute kidney injury
}

This article was published in the following Dove Press journal:

International Medical Case Reports Journal

29 July 2016

Number of times this article has been viewed

\author{
Seung Won Ahn' \\ Tong Yoon Kim' \\ Sangmin Lee' \\ Jeong Yeon Jeong' \\ Hojoon Shim' \\ Yu min Han' \\ Kyu Eun Choi' \\ Seok Joon Shin ${ }^{1,2}$ \\ Hye Eun Yoon ${ }^{1,2}$
}

'Department of Internal Medicine, College of Medicine, The Catholic University of Korea, Seoul, ${ }^{2}$ Division of Nephrology, Department of Internal medicine, Incheon St. Mary's Hospital, Incheon, Republic of Korea
Correspondence: Hye Eun Yoon Division of Nephrology, Department of Internal Medicine, Incheon St. Mary's Hospital, College of Medicine, The Catholic University of Korea, 222 Banpo-daero, Seocho-gu, 137-70I, Incheon, Republic of Korea

Tel +82 322805886

Fax +82 322805987

Email berrynana@catholic.ac.kr
Abstract: Adrenal insufficiency is an uncommon cause of hypercalcemia and not easily considered as an etiology of adrenal insufficiency in clinical practice, as not all cases of adrenal insufficiency manifest as hypercalcemia. We report a case of secondary adrenal insufficiency presenting as hypercalcemia and acute kidney injury in a 66-year-old female. The patient was admitted to the emergency department with general weakness and poor oral intake. Hypercalce$\operatorname{mia}(11.5 \mathrm{mg} / \mathrm{dL})$ and moderate renal dysfunction (serum creatinine $4.9 \mathrm{mg} / \mathrm{dL}$ ) were shown in her initial laboratory findings. Studies for malignancy and hyperparathyroidism showed negative results. Basal cortisol and adrenocorticotropic hormone levels and adrenocorticotropic hormone stimulation test confirmed the diagnosis of adrenal insufficiency. With the administration of oral hydrocortisone, hypercalcemia was dramatically resolved within 3 days. This case shows that adrenal insufficiency may manifest as hypercalcemia and acute kidney injury, which implicates that adrenal insufficiency should be considered a cause of hypercalcemia in clinical practice.

Keywords: hypercalcemia, adrenal insufficiency, acute kidney injury

\section{Introduction}

Hypercalcemia is a common disease found in emergency departments and in-patients. Although primary hyperparathyroidism and malignancy are the most common causes of hypercalcemia, adrenal insufficiency is a rare but important cause of hypercalcemia. ${ }^{1}$ As not all cases of adrenal insufficiency present with hypercalcemia, adrenal insufficiency is not easily considered an etiology of hypercalcemia. The prevalence of hypercalcemia at the time of diagnosis of Addison's disease is reported to be $\sim 5.5 \%-6.0 \%{ }^{2}$ Previous studies have reported hypercalcemia associated with adrenal insufficiency; however, hypercalcemia and acute kidney injury (AKI) related with adrenal insufficiency is rarely reported. Here, we report a case of adrenal insufficiency that presented as hypercalcemia and AKI.

\section{Case presentation}

A 66-year-old female presented to the emergency department with 1 week duration of general weakness and poor oral intake. She had an underlying disease of diabetes and hypertension for 10 years and had been treated with medications at the local clinic, which included metformin, glimepiride, hydrochlorothiazide, losartan, and atorvastatin. She also had severe osteoarthritis at both knee joints and had multiple steroid injections at the local orthopedic clinic. Approximately 2 weeks before admission, she had been admitted for treatment of urinary tract infection (UTI). At that time, blood 
culture and urine culture showed growth of Escherichia coli and was treated with ceftriaxone and tazobactam. She was not on any antihypertensive medication for 2 weeks.

Physical examination showed the following findings: height $152 \mathrm{~cm}$, body weight $57 \mathrm{~kg}$, blood pressure 70/50 $\mathrm{mmHg}$, heart rate 70 beats per minute, and respiratory rate 20 per minute, with body temperature $36.5^{\circ} \mathrm{C}$. Decreased skin and tongue turgor were observed. Pulmonary, cardiac, abdominal, and neurologic examinations were unremarkable.

Table 1 shows the laboratory data at admission and those 2 weeks before admission. Her outpatient laboratory data checked at 2 weeks prior to admission showed normal levels of serum creatinine and calcium. Serum magnesium level

Table I Laboratory data on admission and 2 weeks before

\begin{tabular}{|c|c|c|c|}
\hline Variable & $\begin{array}{l}\text { Reference } \\
\text { range }\end{array}$ & $\begin{array}{l}\text { On } \\
\text { admission }\end{array}$ & $\begin{array}{l}\text { Two } \\
\text { weeks } \\
\text { before }\end{array}$ \\
\hline Hematocrit (\%) & $40.0-48.0$ & 39.7 & 34.4 \\
\hline Hemoglobin $(g / d L)$ & $13.0-18.0$ & 13.7 & 11.7 \\
\hline White cell count $\left(10^{9} / \mathrm{L}\right)$ & $4.0-10.0$ & 13.0 & 6.71 \\
\hline \multicolumn{4}{|l|}{ Differential count $(\%)$} \\
\hline Neutrophils & $45-75$ & 36.0 & 39.2 \\
\hline Lymphocytes & $20-50$ & 39.6 & 41.6 \\
\hline Monocytes & $2-9$ & 17.5 & 11.6 \\
\hline Eosinophils & $0-5$ & 5.5 & 6.6 \\
\hline Basophils & $0-2$ & 1.4 & 1.0 \\
\hline Platelet $\left(10^{9} / \mathrm{L}\right)$ & $140-450$ & 350 & 530 \\
\hline Sodium (mmol/L) & $135-145$ & 132 & 140 \\
\hline Potassium (mmol/L) & $3.5-5.5$ & 3.4 & 3.5 \\
\hline Chloride (mmol/L) & $98-110$ & 96 & 105 \\
\hline Urea nitrogen $(\mathrm{mg} / \mathrm{dL})$ & $6.0-20.0$ & 37.9 & 13.0 \\
\hline Creatinine $(\mathrm{mg} / \mathrm{dL})$ & $0.68-1.30$ & 4.9 & 0.6 \\
\hline MDRD-GFR (mL/minutes/l.73 $\left.\mathrm{m}^{2}\right)$ & & 9.66 & 93.64 \\
\hline Calcium $(\mathrm{mg} / \mathrm{dL})$ & $8.6-10.2$ & 11.5 & 9.4 \\
\hline Phosphorus (mg/dL) & $2.7-4.5$ & 3.6 & 4.1 \\
\hline Magnesium (mg/dL) & $1.6-2.6$ & 1.6 & 2.0 \\
\hline Total bilirubin (mg/dL) & $<1.0$ & 1.0 & 0.6 \\
\hline Aspartate aminotransferase (U/L) & $0-40$ & 20 & 13 \\
\hline Alanine aminotransferase $(\mathrm{U} / \mathrm{L})$ & $0-40$ & 16 & 16 \\
\hline Total protein (g/dL) & $6.6-8.7$ & 5.9 & 6.0 \\
\hline Albumin $(g / d L)$ & $3.4-4.8$ & 2.8 & 2.9 \\
\hline \multicolumn{4}{|l|}{ Urinalysis } \\
\hline Specific gravity & $1.003-1.030$ & 1.016 & \\
\hline $\mathrm{pH}$ & $4.8-7.5$ & 5.0 & \\
\hline Protein & Negative & Negative & \\
\hline Glucose & Negative & Negative & \\
\hline Ketone & Negative & Negative & \\
\hline Nitrite & Negative & Negative & \\
\hline Bilirubin & Negative & Negative & \\
\hline Blood & Negative & Negative & \\
\hline Microscopic white blood cell & $0-3 / \mathrm{HPF}$ & 20-29/HPF & \\
\hline Microscopic red blood cell & $0-I / H P F$ & 5-9/HPF & \\
\hline Epithelial cell & $0-\mathrm{I} / \mathrm{HPF}$ & $\mathrm{I}-4 / \mathrm{HPF}$ & \\
\hline Urine bacteria & Negative & Some & \\
\hline
\end{tabular}

Abbreviations: HPF, high power field; MDRD-GFR, modification of diet in renal disease-glomerular filtration rate. decreased to a lower limit of normal range at admission. Fractional excretion of sodium was $1.0 \%$.

Having pyuria and hypotension, with a previous history of UTI, she was first diagnosed as UTI sepsis. She was admitted to the intensive care unit and antibiotics and massive hydration ( $30 \mathrm{~mL} / \mathrm{kg}$ of crystalloids) were administered. The patient's vital signs were stabilized after administration of crystalloids. Within 2 days, inflammatory signs and blood pressure were normalized. However, serum calcium and creatinine levels remained elevated, and the patient constantly complained about poor oral intake and general weakness.

On the third hospital day, administration of saline and calcitonin (40 IU per day) was begun. Serum calcium level decreased for the next 2 days (from 11.9 to $9.9 \mathrm{mg} / \mathrm{dL}$ ) but began to increase again from the third day of calcitonin administration.

To evaluate the cause of hypercalcemia, contrastenhanced computed tomography of chest and abdomen and whole body bone scintigraphy were performed, but the results showed no evidence of malignancy. Serum and urine protein electrophoresis, anti-neutrophil cytoplasmic antibody titers, and tumor marker studies were negative. Thyroid function profile revealed normal levels of thyroid stimulating hormone $(0.68 \mu \mathrm{IU} / \mathrm{L}$, normal range: $0.34-0.56 \mu \mathrm{IU} / \mathrm{L})$ and free thyroxine $(1.12 \mathrm{ng} / \mathrm{dL}$, normal range: $0.58-1.64 \mathrm{ng} / \mathrm{dL})$. The bone mineral density $T$-score was -1.4 , which indicated osteopenia. Intact parathyroid hormone (PTH) was $7.5 \mathrm{pg} / \mathrm{mL}$ (normal range: 12-88 pg/mL), PTH-related peptide was undetectable (normal range: $<1.1 \mathrm{pmol} / \mathrm{L}$ ), and serum 25-hydroxy vitamin D was $16.32 \mathrm{ng} / \mathrm{mL}$ (normal range: $30-100 \mathrm{ng} / \mathrm{mL}$ ). These results indicated a suppressed PTH-vitamin D axis.

We found that the patient had multiple steroid injections in both her knee joints in the past, although the amount of steroid could not be quantified. Adrenocortical function was assessed, and showed that her serum cortisol level was $2.36 \mu \mathrm{g} / \mathrm{dL}$ and adrenocorticotropic hormone (ACTH) was $32.51 \mathrm{pg} / \mathrm{mL}$ (normal range: $10-60 \mathrm{pg} / \mathrm{mL}$ ). The ACTH stimulation test showed inadequate cortisol response to the pharmacological dose of ACTH (Table 2). As most people with secondary adrenal insufficiency fall within the range limit and usually below 35, the plasma ACTH level and ACTH stimulation test results suggested the diagnosis of

Table 2 The ACTH stimulation test

\begin{tabular}{llllll}
\hline Time (minutes) & 0 & 30 & 60 & 90 & 120 \\
Cortisol $(\mu \mathrm{g} / \mathrm{dL})$ & 2.36 & 9.37 & 11.43 & 12.85 & 10.21 \\
\hline
\end{tabular}

Note: Cortisol reference range $(6.7-22.6 \mu \mathrm{g} / \mathrm{dL})$.

Abbreviation: ACTH, adrenocorticotropic hormone. 


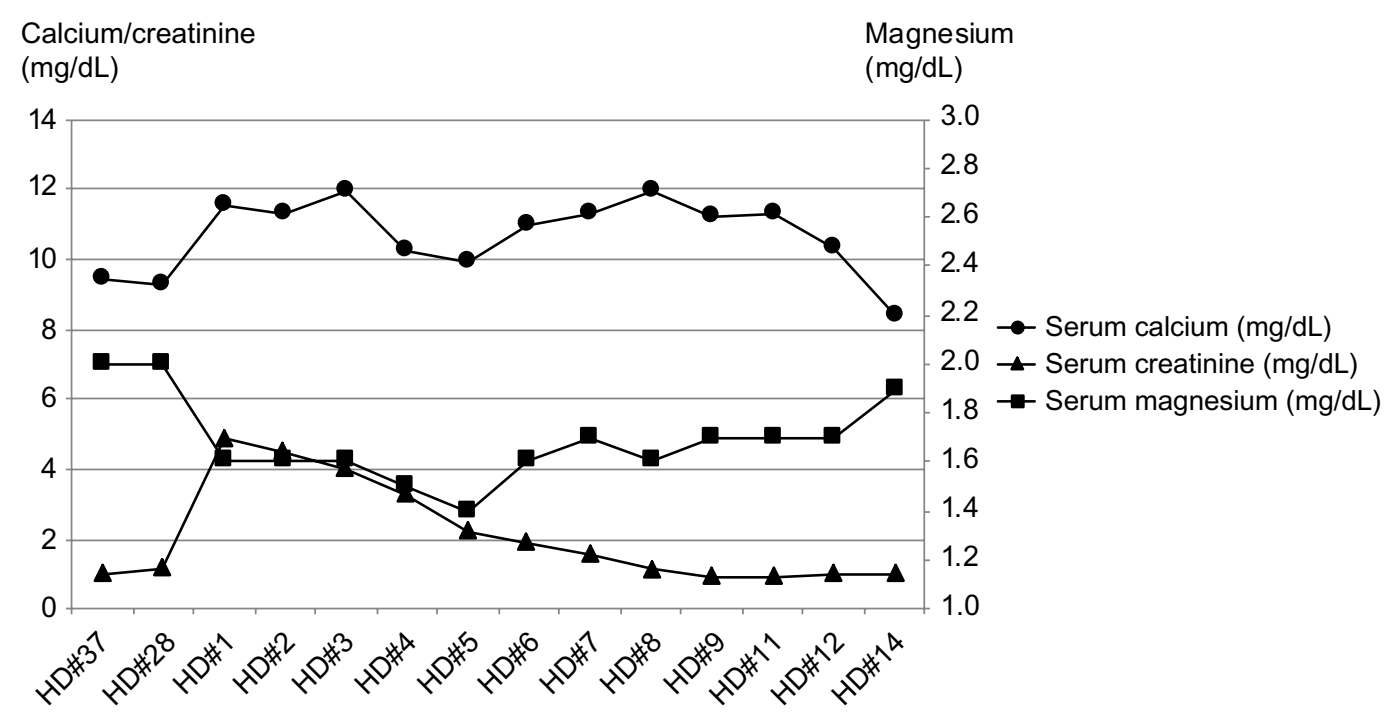

Hospitalization in days (HD)

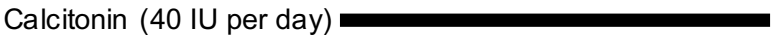

Hydrocortisone $(1.5 \mathrm{mg} / \mathrm{kg})$

Figure I Clinical course of serum calcium, magnesium, and creatinine level.

secondary adrenal insufficiency. ${ }^{3}$ Hydrocortisone $(1.5 \mathrm{mg} / \mathrm{kg})$ was administered from the tenth hospital day. Her serum calcium level returned to normal within 3 days and her general weakness and anorexia were completely improved (Figure 1). With the normalization of calcium level, magnesium level trended toward normal range. After 2 weeks of follow-up, serum calcium level was maintained at $8.7 \mathrm{mg} / \mathrm{dL}$. As the patient was at a high risk of developing osteoporosis and needed corticosteroid replacement, regular monitoring for bone mineral density was considered, but the patient was lost for follow-up.

\section{Discussion}

Hypercalcemia is a common finding in patients in emergency and in-patients. Although hypercalcemia can be related with adrenal insufficiency, adrenal insufficiency is not easily considered a cause of hypercalcemia. In this case, thorough evaluation for malignancy and parathyroid disease failed to make the diagnosis, but a test for adrenocortical function demonstrated the cause of hypercalcemia and AKI, and glucocorticoid replacement resolved hypercalcemia.

In this case, the patient had an unclear history of steroid injections. It was certain that the patient had multiple steroid injections in both her knee joints, but the amount of intra-articularly administered glucocorticoids could not be quantified. The prevalence of adrenal insufficiency secondary to locally applied glucocorticoids is not clear. According to one study, a single injection of intra-articularly administered glucocorticoids can cause adrenal suppression. ${ }^{4}$ The intraarticular injections of glucocorticoid medication might have interfered with normal pituitary function and caused secondary adrenal insufficiency.

It is reported that the prevalence of hypercalcemia is $-5.5 \%-6.0 \%$ at the time of diagnosis of Addison's disease. ${ }^{2}$ Previous studies have reported hypercalcemia associated with adrenal insufficiency; however, hypercalcemia and AKI related with adrenal insufficiency is rarely reported. The development of renal injury in individuals with hypercalcemia is related to the degree and duration of hypercalcemia. Long-standing hypercalcemia and hypercalciuria can lead to nephrogenic diabetes insipidus, nephrolithiasis, nephrocalcinosis, tubular atrophy with interstitial fibrosis and, thus, chronic kidney disease. Hypercalcemia can lead to a decrease in the glomerular filtration rate mediated by direct renal vasoconstriction and natriuresis-induced volume contraction. ${ }^{5,6}$ In this case, hypercalcemia can be the cause of AKI. However, the patient had hypotension and UTI at the arrival of emergency department and these could have had influence on the renal function. The fractional excretion of sodium was calculated to be $1 \%$ and in the urinary sediment, epithelial cells were present, which indicates that acute tubular necrosis may be present. Considering these results, in our opinion, the patient's AKI was due to a mixture of prerenal (hypotension) and intrinsic (UTI sepsis and hypercalcemia) causes. 
Patients with hypercalcemia can develop mild hypomagnesemia. This is partially explained by the fact that calcium and magnesium functionally compete for transport in the thick ascending limb of the loop of Henle. ${ }^{7}$ In this case, the initial magnesium level was $1.6 \mathrm{mg} / \mathrm{dL}$, which was at the lower borderline of the normal range. Although the PTH level was not checked after the normalization of calcium and magnesium level, considering the change in magnesium level along with calcium level, we speculate that hypercalcemia caused hypomagnesemia and that both hypercalcemia and hypomagnesemia suppressed the PTH level.

Though the mechanism of hypercalcemia in adrenal insufficiency is unknown in detail, a number of mechanisms are thought to be the possible cause. First, adrenal insufficiency causes hypovolemia and a consequent reduction in glomerular infiltration rate. Decreased glomerular infiltration rate results in reduction in the amount of calcium filtered at the glomerulus, and increased calcium renal reabsorption in proximal tubule. ${ }^{8,9}$ Rehydration with normal saline will normalize the glomerular filtration rate as well as the level of filtered calcium. Second, the enzyme activity of 1-alphahydroxylase may be increased in adrenal insufficiency. The 1-alpha-hydroxylase is a renal enzyme that participates in conversion of calcidiol to the active form of vitamin $\mathrm{D}$, calcitriol, leading to increased intestinal absorption of calcium. ${ }^{10}$ As prednisone inhibits 1-alpha-hydroxylase, thus reducing hypercalcemia, adrenal insufficiency may result in hypercalcemia. Third, a decrease in circulating stanniocalcin, a paracrine hormone secreted from the adrenal gland, could result in reduced levels of circulating calcium. Deficient adrenal hormone and decreased level of stanniocalcin may affect skeletal calcium efflux into circulation and result in hypercalcemia. ${ }^{11}$

In conclusion, this case shows that adrenal insufficiency may cause hypercalcemia, and it can present as hypotension and AKI. After excluding more common diseases, such as malignancy and primary hyperparathyroidism, the possibility of adrenal insufficiency should be considered the cause of hypercalcemia, especially in elderly patients with a history of glucocorticoid injection.

\section{Acknowledgment}

This research was supported by Basic Science Research Program through the National Research Foundation of Korea (NRF) funded by the Ministry of Science, ICT and Future Planning (2014R1A1A3A04050919). Written informed consent and ethical approval from a review board were unnecessary because it was a retrospective case review.

\section{Disclosure}

The authors report no conflicts of interest in this work.

\section{References}

1. Jacobs TP, Bilezikian JP. Clinical review: Rare causes of hypercalcemia. J Clin Endocrinol Metab. 2005;90(11):6316-6322.

2. Nerup J. Addison's disease - clinical studies. A report for 108 cases. Acta Endocrinol (Copenh). 1974;76(1):127-141.

3. Raff H, Sharma ST, Nieman LK. Physiological basis for the etiology, diagnosis, and treatment of adrenal disorders: Cushing's syndrome, adrenal insufficiency, and congenital adrenal hyperplasia. Compr Physiol. 2014;4(2):739-769.

4. Borresen SW, Klose M, Rasmussen AK, Feldt-Rasmussen U. Adrenal insufficiency caused by locally applied glucocorticoids-myth or fact? Curr Med Chem. 2015;22(23):2801-2809.

5. Araujo CA, Araujo NA, Daher EF, et al. Resolution of hypercalcemia and acute kidney injury after treatment for pulmonary tuberculosis without the use of corticosteroids. Am J Trop Med Hyg. 2013;88(3):592-595.

6. Williams PF, Thomson D, Anderton JL. Reversible renal failure due to isolated renal sarcoidosis. Nephron. 1984;37(4):246-249.

7. Moe SM. Disorders involving calcium, phosphorus, and magnesium. Prim Care. 2008;35(2):215-237, v-vi.

8. Bhatti RS, Flynn MD. Adrenal insufficiency secondary to inappropriate oral administration of topical exogenous steroids presenting with hypercalcaemia. BMJ Case Rep. 2012;2012.

9. Lee AS, Twigg SM. Opioid-induced secondary adrenal insufficiency presenting as hypercalcaemia. Endocrinol Diabetes Metab Case Rep. 2015;2015:150035.

10. Minisola S, Pepe J, Piemonte S, Cipriani C. The diagnosis and management of hypercalcaemia. BMJ. 2015;350:h2723.

11. Kato A, Shinozaki S, Goga T, Hishida A. Isolated adrenocorticotropic hormone deficiency presenting with hypercalcemia in a patient on long-term hemodialysis. Am J Kidney Dis. 2003;42(2):E32-E36.
International Medical Case Reports Journal

Publish your work in this journal

The International Medical Case Reports Journal is an international, peer-reviewed open-access journal publishing original case reports from all medical specialties. Previously unpublished medical posters are also accepted relating to any area of clinical or preclinical science. Submissions should not normally exceed 2,000 words or

\section{Dovepress}

4 published pages including figures, diagrams and references. The manuscript management system is completely online and includes a very quick and fair peer-review system, which is all easy to use. Visit $\mathrm{http}: / /$ www.dovepress.com/testimonials.php to read real quotes from published authors. 